\title{
Effect of Tele-nursing Instructions on Women Knowledge and Beliefs about Cervical Cancer Prevention
}

\author{
Tahany El-Sayed El-Sayed Amr ${ }^{1}$, Reda Mohamed Elsayed Ramadan ${ }^{2}$, Asmaa Ghareeb Mohamed ${ }^{3} \&$ Reda \\ M.Nabil Aboushady ${ }^{4}$ \\ 1. Assistant Professor of Maternal and Newborn Health Nursing, Faculty of Nursing, Menoufia University, Egypt- \\ College of Applied Medical Sciences, Shaqra University, KSA \\ 2. Medical Surgical Nursing, Faculty of Nursing, Ain Shams University, Egypt \\ 3. Assistant professor of community Health Nursing, Faculty of Nursing, Assiut University, Egypt. \\ 4. Maternal and Newborn Health Nursing, Cairo University, Egypt.
}

\begin{abstract}
Worldwide, the cervical cancer considered the most frequent gynecological cancer among women. Effective primary and secondary prevention approaches will prevent most cervical cancer cases. Aim of the study: is to assess the level of women's knowledge and beliefs regarding cervical cancer prevention and to implement and examine the effectiveness of tele-nursing instructions on women based on Health Belief Model. Methods: A quasi-experimental design was used. This study was conducted at primary health care center and outpatient clinic at Shaqra city, KSA. A convenience sample of 75 women were enrolled in the study. Three tools were used to collect data, 1) structured interviewing questionnaire, 2) structured cervical cancer knowledge questionnaire \& 3) Health Belief Model Scale Results: There was a statistically significant difference regarding level of knowledge after applying Tele- nursing based on Health Belief Model. In addition, there was a statistical difference regarding sub-scale of health belief model and increasing in mean percentage after intervention among study sample. Conclusion: Tele- nursing education through the application of the Health Belief Model proved massive changes in improving both the beliefs of the participating women, as well as the level of their knowledge about cervical cancer prevention. Recommendation: Enhancement of tele-nursing instruction use in many nursing practice settings and developing future research prevention programs that cover a large sample would be of a great importance in early detection and management.
\end{abstract}

\section{Keywords: Cervical cancer, Knowledge, Health Belief Model \& Tele-nursing.}

\section{Introduction:}

The cervix cancer had categorized as $4^{\text {th }}$ most public female cancer among females worldwide (Ferlay, et al. 2015). It had enormously a huge effect on the lower resources' nations; where about $90 \%$ of the cervical cancer-related deaths can be happened in these countries (Castle and Pierz, 2019; Arbyn et al., 2020, \& Alreshidi, et al., 2020). About 528.000 per year is the number of cervical cancer cases in the world. It is also measured to be the second most common cancers in developing countries (Aldohain et al., 2019). High death rate of cervical cancer in developing countries is due to many causes; only $5 \%$ of spending on cervical prevention programs was paid by developed countries globally (Ferdous et al., 2016). Cancer of the cervix positions as $9^{\text {th }}$ women cancer in the Gulf Arab States. The highest occurrence was in Oman (58\%) and the lowest in the United Arab Emirates (10\%) (Alkhalawi et al., 2019). It is categorizing a twelfth of all females'cancers accounting for $2.4 \%$ of all new cases of cancer In Saudi Arabia (Alsbeih, 2014). In 2014, new cases incidence of cervical cancer was 1.9 per 100,000 (AlZahrani, 2014). A recent study by (Al-Mandeel, et al., 2016) had certained that, cervical cancer became the third most public gynecological malignancy in Saudi women. However, in Saudi Arabia near to $40 \%$ of women diagnosed with this problem at late stages. Lack of effective prevention and screening programs in Saudi Arabia lead to delayed in detection of the disease in early stage.

Human papillomavirus (HPV) types are the main cause in activating the growth of cervical cancer (Arbyn, et al., 2020 \& WHO, 2018). HPV is a sexually transmitted infection (Alnafisah, et al., 2019). Furthermore, other factors associated with this cancer as genetic predisposition, smoking, compromised immunity, early sexual debut, multiple sexual partners, and lack of disease awareness (Kumar et al., 2007 \& Urasa et al., 2011). A huge financial and social burden is related to this problem. It is a social disease, especially for the poor and the less educated, which are at risk factors (Amotsuka, 2013).

Firstly, there were neither signs nor symptoms in women with initial cervical cancer and precancerous lesions. When metastases start to occur, the most common symptoms include abnormal vaginal 
bleeding after sex, douching, menopause, bleeding and spotting between periods, heavy or long menstrual period than usual; pain during sex and abnormal vaginal discharge. Further with advanced cervical cancer women can suffer from pelvic pain, loss of appetite, weight loss, and decrease in red platelets (Bodurka et al., 2011). It was evidenced that, providing regular cervical screening services to all women who have been sexually active, doing HPV test, Pap smears or the Visual Inspection of the Acetic Acid painted cervix (VIA),and vaccination against the HPV before the beginning of sexual activity were effective in prevention this disease (Obstetricians, 2003).

Tele-nursing is a component of tele-health that occurs when staff nurses meet the health needs of patients using information, communication and web-based systems. This has been defined as the delivery, management and coordination of care, and services provided through information and telecommunication technologies (Schlachta, 2015). This technology helps to rapid access of better services, decrease cost and facilitate easy access to the most appropriate specialized skills and increase the quality of the provision of health services to patients. (Massarat etal, 2011). Furthermore, through tele-nursing training and remote consultation for patients can be provided by email for patients and their relatives. (McGonigle \& Mastrian, 2008)

Tele-health is defined as "the use of electronic information and telecommunication technologies to support and promote long-distance clinical healthcare, patient and professional health-related education, public health and health administration" (Health \& Human Services Department, 2020). Tele-nursing is a subcategory of tele-health which concerned on the transfer, management, and coordination of care and administrations utilizing using telecommunications technology innovation inside the nursing field (Dunk et al., 2004). Nowadays, telephone is an accessible communication method used for telenursing. It has several uses in our society to helps access of care services, and improves the relationship between patients \& caregivers (Zakeri et al., 2009).

The Health Belief Model (HBM) focuses on a person's healthy behavior to predict future actions (Yakout et al., 2016). It is an appropriate needs assessment model that is very useful for health developers to plan intervention practices (Ogden, 2009). According to the HBM, to accept preventive measures, a person must see the risk of the problem, understand the complexity of the complications, and in case of the positive evaluation of the benefits a preventive behavior will be adopted (Shojaeezadeh et al., 2011). Furthermore, the choice to participate in prevention programs controlled by many factors as perceived susceptibility to the health condition, perceived severity, perceived benefits of undertaking screening, perceived barriers and budgets of the screening approaches (Abolfotouh, 2015).

Both primary and secondary levels of prevention can make cervical cancer occurrence and death largely avoidable when implemented (Arbyn, et al., 2020). So, nurses have an important mission to convey information about risk factors, early signs detection of cervical cancer and women encouragement for regular cervical cancer screening. This can be achieved by conducting additional educational programs for nurses who is considered a vital cog in the healthcare delivery system (Naik et al., 2012; \& Mali, 2014). Several studies assured that, effective female education on cervical cancer and screening was recognized, among other strategies, as a way to increase awareness about cancer screening services (Nwankwo et al., 2011; Oche et al., 2013 \& Anyebe et al., 2014). Therefore, the current study contributes to assess, implement and examine the effectiveness of tele-nursing instruction on the women level of knowledge and beliefs towards cervical cancer prevention based on HBM. Therefore, the current study aimed to assess women knowledge level and evaluate the effectiveness of Tele-nursing instruction on women level of knowledge and beliefs based on HBM.

Significance of the study:

Cervical cancer is a preventable and curable disease if early diagnosed. Tele-nursing raises patients' access to an influencer and effective nursing (Zakeri et al., 2009). Studies have shown that mobile health applications may be a useful tool to facilitate improvement of communication between patients and health care providers (Becker et al., 2014, Whitehead \& Seaton, 2016). Many factors contributes to cervical cancer occurrence such as lack of screening programs, limited access to care, certain behavioral factors, values and beliefs. (Richardsonet al., 2011). Thus, application of HBM is used widely to assess the health beliefs on the screening behaviors, aids to forecast behavior, and health promotion activities (McEwen \& Wills, 2014).

Aim of the study:

The current study aimed to:

1- Assess women knowledge level regarding cervical cancer prevention after Tele-nursing instruction implementation.

2- Implement and evaluate the effectiveness of Telenursing instruction on women's level of knowledge and beliefs based on Health Belief Model. 


\section{Research Hypothesis}

Women who will receive the Tele-nursing instruction about cervical cancer prevention; their knowledge and belief were affected positively.

\section{Subjects \& Methods Study design}

The quasi-experimental design was adopted to carry out this study.

\section{Setting}

The study was carried out at primary health care center and outpatient clinic at Shaqra hospital, Shaqra city, Riyadh, Kingdom of Saudi Arabia (KSA) which provides secondary and tertiary level of service such as (Medical, Gynecological examination \& treatment).

\section{Sample:}

A convenient sample of 75 women were recruited after their acceptance to share in the study. The women were enrolled based on the inclusion and exclusion criteria. Inclusion criteria includes: married women, did not receive any nursing education before regarding cervical cancer prevention. Exclusion criteria includes: Women had learning disabilities, undergoing psychiatric treatment.

Sample size: A total of (75) women were selected according to the following statistical formula $\mathrm{n}=\mathrm{Z} 2 \mathrm{p}$ (1-p) /d2, where $\mathrm{z}=$ level of confidence according to the standard normal distribution (for a level of confidence of $95 \%, \mathrm{z}=1.96) . \mathrm{p}=$ estimated proportion of the population that presents the characteristic (when unknown we use $p=0.5), d=(d$ is considered 0.05 ).

\section{Data collection tools}

Four tools were used to collect data.

Tool I: Structured interviewing questionnaire: it was developed by researchers and consisted of two parts. Part (1): Includes demographic data such as age, educational level, occupation, etc. Part (2): Includes family and obstetric history (e.g. family history of cervical cancer, age at marriage, duration of marriage, etc). The researchers prepared a supportive material (instructional booklet) after reviewing related literature regarding cervical cancer prevention based on evidence-based nursing and given to all study participated women. The booklet includes definition, risk factors, symptoms, and how to prevent cervical cancer in Arabic language.

Tool II: Cervical cancer Knowledge tool: it was designed by the researchers to measure the level of knowledge regarding cervical cancer, it contains 17 items. The researchers read each question and ask the women to give an answer either true or false. The scoring system was (0) if the answer is false and (1) if the answer is true with the total grade of 17 . The total knowledge scores were classified into three levels: score less than $50 \%$ was considered poor, $50-70 \%$ was considered satisfactory and good level of knowledge when more than70 percentage. The reliability of the tool was done using Cronbach's alpha ( $\mathrm{r}=0.84)$.

Tool III: Health Belief Model Scale: It was developed by Champion (1999) and adapted by the researchers after reviewing available related literature. HBM scale covers five subscales and included 39 items (seven items for perceived susceptibility, 10 items for perceived severity, five items for perceived benefits, 10 items for perceived barrier, and seven items for cues to action). All the items of subscales have three-point likert scale response choices: agree scores 3 points, neutral scores 2 points, and disagree scores 1 point. The total score ranged from 1 to 117 points, which were scored as follows: 21 for perceived susceptibility, 30 for perceived severity, 15 for perceived benefits, 30 for perceived barrier, and 21 for cues to action. The tool was translated into 2 ways from English to Arabic and from Arabic to English to ensure accuracy. The reliability of the whole tool was done using Cronbach's alpha ( $\mathrm{r}=0.88)$.

Validity and Reliability of the tool

Tools of data collection were submitted to and reviewed by a panel of experts in the fields of nursing, to test the face and content validity. Each of the experts was requested to examine tools for content coverage, clarity, wording, length, format, and overall appearance. Modifications were done according to the panel's judgment on the clarity of sentences and content appropriateness as "rephrasing and canceling for four questions" were done. Reliability analysis was conducted to investigate the instrument internal consistency, which used in the study; Cronbach's alpha coefficients were calculated to examine the measurement reliability with multipoint items.

\section{Procedure}

An official permission was taken prior to starting data collection from the administrative authority. All women who met the inclusion criteria were included in the study. The aim of the study was explained to the participants in order to be obtain their oral acceptance to be recruited in the study as well as to gain their cooperation. The researchers attended the outpatient clinic three days per week starting from 9.00 a.m. until 12:00 p.m. The study was conducted through: recruitment and interviewing, implementation, and evaluation.

Recruitment and Interviewing: Recruitment of women was carried out from May 2019 and was completed by January 2020. The interview took approximately 30 minutes for each woman; their 
answers were filled in the questionnaire. All studied women were received telephone instruction. The content of the phone conversations were based on a support instructional module that was prepared by the researchers after reviewing evidenced based research and comprehensive literature. All participated women were divided into five groups with an average number of 10-15 woman. In each telephone call, researchers asked women if they had adapted the instructions given previously. The other part of the conversation was about giving information related to cervical cancer prevention and before ending the call, the women were again invited to ask their questions.

Telephone interviews were performed once weekly. The total frequency of telephone conversations was averaged five calls for each, each session lasted about 30-45 minutes using power point presentation, brochures, and group discussion sent via phone support services.

In the first session, points regarding definition, incidence, clinical features, and diagnostic test for cervical cancer were discussed by the researchers. The second session contained the followings: who gets cervical cancer and risk factors; and finally, the third session includes way of prevention regarding cervical cancer.

Evaluation was emphasized on estimating the effect of the tele-nursing service on women's knowledge and belief regarding cervical cancer prevention based on HBM twice pre and post (after 3 months) telenursing service implementation.

\section{Ethical consideration:}

An official permission was requested and obtained from the authoritative committee to conduct the study. Women were invited to share in the study after full explanation of the study aim. Informed oral consent was obtained from the participants to be interviewed. Furthermore, women were assured that they can withdraw from the study at any time, without penalty, if they so wished. Assigning codes rather than participants' names to maintain the anonymity were used. The participants were allowed to ask questions. They also informed that the study findings would be published in the form of presentations at conferences or in an accredited journal.

\section{Pilot Study:}

A pilot study was carried out on $8(10 \%)$ participant of the total study sample. It was done to examine the relevance, clarity and content validity of the tools, as well as to evaluate the time needed for women to fill the questionnaires and to assess the problems and obstacles that might face the researchers during data collection. The pilot study sample were included in the total study number as there were no modifications on the tools.

\section{Statistical Analysis:}

After completion of data collection, data were revised, coded, computed and analyzed using statistical package for social sciences (SPSS) version 23. Frequency distribution, percentages, mean and standard deviation were calculated, Chi-square and Paired sample T-test were used to describe the level of statistical significance which considered at $\mathrm{p}<$ 0.05 . 
Table (1): Distribution of the studied sample regarding their socio-demographic characteristics $(n=75)$

\begin{tabular}{|c|c|c|}
\hline \multirow{2}{*}{ Socio- demographic characteristics } & \multicolumn{2}{|c|}{ Study sample $(n=75)$} \\
\hline & No. & $\%$ \\
\hline $\begin{array}{l}\text { Age }(\text { years old }) \\
:<30 \\
: 30-40 \\
: \geq 40\end{array}$ & $\begin{array}{c}5 \\
37 \\
33\end{array}$ & $\begin{array}{c}6.7 \% \\
49.3 \% \\
44 \%\end{array}$ \\
\hline Mean \pm SD $($ years old $)$ & \multicolumn{2}{|c|}{$39.25 \pm 6.08$} \\
\hline $\begin{array}{l}\text { Educational qualification } \\
\text { - Read and write } \\
\text { - Primary school } \\
\text { - Secondary school } \\
\text { - University level }\end{array}$ & $\begin{array}{c}17 \\
8 \\
33 \\
17\end{array}$ & $\begin{array}{c}22.7 \% \\
10.7 \% \\
44 \% \\
22.7 \%\end{array}$ \\
\hline $\begin{array}{l}\text { Residence } \\
\text { - Urban } \\
\text { - Rural }\end{array}$ & $\begin{array}{l}17 \\
58\end{array}$ & $\begin{array}{c}22.75 \\
77.3 \%\end{array}$ \\
\hline $\begin{array}{l}\text { Work } \\
\text { - Working } \\
\text { - House wife }\end{array}$ & $\begin{array}{l}50 \\
25\end{array}$ & $\begin{array}{l}66.7 \% \\
33.3 \%\end{array}$ \\
\hline $\begin{array}{l}\text { Type of working } \\
\text { - Secretary } \\
\text { - Administrator } \\
\text { - Teacher }\end{array}$ & $\begin{array}{l}23 \\
20 \\
7\end{array}$ & $\begin{array}{l}30.7 \% \\
26.7 \% \\
9.3 \%\end{array}$ \\
\hline $\begin{array}{l}\text { Level of income } \\
\text { - Enough and saving } \\
\text { - Enough } \\
\text { - Not enough }\end{array}$ & $\begin{array}{c}8 \\
56 \\
11\end{array}$ & $\begin{array}{l}10.7 \% \\
74.7 \% \\
14.7 \%\end{array}$ \\
\hline
\end{tabular}

Table (2): Distribution of the studied sample regarding their Obstetrical history (no. $=75$ )

\begin{tabular}{|c|c|c|}
\hline \multirow{2}{*}{ Variables } & \multicolumn{2}{|c|}{$\begin{array}{c}\text { Study sample } \\
(n=75)\end{array}$} \\
\hline & No. & $\%$ \\
\hline $\begin{array}{l}\text { Mean age of menarche(years) } \\
-\mathrm{M} \pm \mathrm{SD}\end{array}$ & \multicolumn{2}{|c|}{$11.92 \pm 0.91$} \\
\hline $\begin{array}{l}\text { Age at marriage }(\text { years }) \\
\bullet<20 \text { years } \\
\bullet \geq 20 \text { years }\end{array}$ & $\begin{array}{l}39 \\
36\end{array}$ & $\begin{array}{l}52 \% \\
48 \%\end{array}$ \\
\hline $\begin{array}{l}\text { Gravidity } \\
\text { - Less than } 3 \\
\text { - More than } 3 \\
\end{array}$ & $\begin{array}{l}23 \\
52\end{array}$ & $\begin{array}{l}30.7 \% \\
69.3 \%\end{array}$ \\
\hline $\begin{array}{l}\text { Parity } \\
\text { - Less than } 3 \\
\text { - More than } 3 \\
\end{array}$ & $\begin{array}{l}16 \\
59\end{array}$ & $\begin{array}{l}21.3 \% \\
78.7 \%\end{array}$ \\
\hline $\begin{array}{l}\text { Use contraceptive method } \\
\text { - Yes } \\
\text { - No }\end{array}$ & $\begin{array}{l}42 \\
33\end{array}$ & $\begin{array}{l}56 \% \\
44 \%\end{array}$ \\
\hline $\begin{array}{l}\text { Type of contraceptive method } \\
\text { - No } \\
\text { - Oral } \\
\text { - IUD } \\
\text { - Mechanical }\end{array}$ & $\begin{array}{c}33 \\
8 \\
14 \\
20\end{array}$ & $\begin{array}{l}44 \% \\
10.7 \% \\
18.7 \% \\
26.7 \%\end{array}$ \\
\hline $\begin{array}{l}\text { Pap smear test } \\
\text { - No } \\
\text { - Yes }\end{array}$ & $\begin{array}{l}63 \\
12\end{array}$ & $\begin{array}{l}84 \% \\
16 \%\end{array}$ \\
\hline
\end{tabular}

Vol, (8) No, (23) Supplement December 2020, pp (153-165) 


\begin{tabular}{|c|c|c|}
\hline \multirow{2}{*}{ Variables } & \multicolumn{2}{|c|}{$\begin{array}{c}\text { Study sample } \\
(\mathrm{n}=75)\end{array}$} \\
\hline & No. & $\%$ \\
\hline $\begin{array}{l}\text { Family history of cervical cancer } \\
\text { - Yes } \\
\text { - No }\end{array}$ & $\begin{array}{l}14 \\
61\end{array}$ & $\begin{array}{l}18.7 \% \\
81.3 \%\end{array}$ \\
\hline $\begin{array}{l}\text { Reason for not perform Pap smear } \\
\text { - Fear from result } \\
\text { - Expensive } \\
\text { - Lack of knowledge } \\
\text { - No barrier }\end{array}$ & $\begin{array}{c}21 \\
4 \\
39 \\
11\end{array}$ & $\begin{array}{l}28 \% \\
5.3 \% \\
52 \% \\
14.7 \%\end{array}$ \\
\hline
\end{tabular}

Table (3): Distribution of the studied sample regarding their Levels of Knowledge Before and After Telenursing Instruction (no. $=\mathbf{7 5}$ )

\begin{tabular}{|c|c|c|}
\hline Level of Knowledge & $\begin{array}{c}\text { Before intervention } \\
\text { No. (\%) }\end{array}$ & $\begin{array}{c}\text { After intervention } \\
\text { No. (\%) }\end{array}$ \\
\hline Poor $\leq 50$ & $30(40 \%)$ & $6(8 \%)$ \\
Satisfactory $50-70$ & $41(54.7 \%)$ & $4(5.3 \%)$ \\
Good $\geq 70$ & $4(5.3 \%)$ & $65(86.7 \%)$ \\
\hline$\chi^{2}=15.62 \quad \mathrm{p}=0.004$ & \multicolumn{2}{|c|}{} \\
\hline
\end{tabular}

Table (4): Distribution of the studied sample regarding Health belief model scale mean score before and after intervention $(\mathbf{n}=\mathbf{7 5})$

\begin{tabular}{|l|c|c|c|}
\hline \multirow{2}{*}{\multicolumn{1}{|c|}{ HBM categories }} & Before intervention & After intervention & \multirow{2}{*}{ p-value } \\
\cline { 2 - 3 } & $\mathrm{M} \pm \mathrm{SD}$ & $\mathrm{M} \pm \mathrm{SD}$ & \\
\hline Perceived susceptibility & $12.10 \pm 4.83$ & $13.74 \pm 5.54$ & $0.002^{*}$ \\
\hline perceived severity & $18.14 \pm 6.79$ & $20.14 \pm 7.14$ & 0.122 \\
\hline Perceived barriers & $18.80 \pm 2.21$ & $21.14 \pm 5.12$ & 0.255 \\
\hline perceived benefits & $8.82 \pm 1.16$ & $10.44 \pm 2.87$ & $0.003^{*}$ \\
\hline cues to action & $12.09 \pm 2.26$ & $10.65 \pm 3.15$ & $0.000^{*}$ \\
\hline
\end{tabular}

Paired sample t-test $\quad *$ Significant $p<0.05$ 
Table (5): Distribution of the Sample according to their beliefs toward cervical cancer prevention (no. $=\mathbf{7 5}$

\begin{tabular}{|c|c|c|c|c|c|c|}
\hline Sub scale of Health belief model & \multicolumn{3}{|c|}{ Before instruction } & \multicolumn{3}{|c|}{ After instruction } \\
\hline Perceived susceptibility & Agree & Neutral & Disagree & Agree & Neutral & Disagree \\
\hline 1.I am at a risk for developing cervical cancer. & $15.3 \%$ & $0 \%$ & $84.7 \%$ & $31.3 \%$ & $4.7 \%$ & $64 \%$ \\
\hline 2.My chances of getting cervical cancer in the next few years are high. & $14.7 \%$ & $69.3 \%$ & $16 \%$ & $31.3 \%$ & $53.3 \%$ & $15.3 \%$ \\
\hline 3.There is a high possibility that I will get cervical cancer. & $14.7 \%$ & $25.3 \%$ & $60 \%$ & $30.7 \%$ & $19.3 \%$ & $50 \%$ \\
\hline 4.If I do not have symptoms; I do not need a Pap screening. & $14.7 \%$ & $34.7 \%$ & $50.7 \%$ & $30.7 \%$ & $27.3 \%$ & $42 \%$ \\
\hline 5.My family history puts me at risk of getting cervical cancer. & $15.3 \%$ & $34 \%$ & $50.7 \%$ & $30.7 \%$ & $27.3 \%$ & $42 \%$ \\
\hline 6.My physical health makes me likely to have cervical cancer. & $14.7 \%$ & $34 \%$ & $51.3 \%$ & $30.7 \%$ & $27.3 \%$ & $42 \%$ \\
\hline 7.I worry a lot about cervical cancer. & $14.7 \%$ & $25.3 \%$ & $60 \%$ & $26 \%$ & $22.7 \%$ & $51.3 \%$ \\
\hline Total mean percentage of perceived susceptibility & \multicolumn{3}{|c|}{$11.30 \pm 4.22$} & \multicolumn{3}{|c|}{$13.04 \pm 5.29$} \\
\hline \multicolumn{7}{|l|}{ Perceived severity } \\
\hline 1.Cervical cancer may lead to death. & & & & & & \\
\hline 2.Cervical cancer may lead to a hysterectomy. & $\begin{array}{l}18 \% \\
18 \%\end{array}$ & $\begin{array}{c}75.3 \% \\
8 \%\end{array}$ & $\begin{array}{l}6.7 \% \\
74 \%\end{array}$ & $\begin{array}{c}32 \% \\
327 \%\end{array}$ & $\begin{array}{l}62.7 \% \\
7.3 \%\end{array}$ & $\begin{array}{l}5.3 \% \\
60 \%\end{array}$ \\
\hline 3.Cervical cancer is a serious health problem. & $18 \%$ & $427 \%$ & $\begin{array}{l}14 \% \\
46 \%\end{array}$ & $\begin{array}{c}32.1 \% \\
28 \%\end{array}$ & $3.3 \%$ & $00 \%$ \\
\hline $\begin{array}{l}\text { 4.Cervical cancer can lead to a female needing chemotherapy or radiotherapy } \\
\text { treatment. }\end{array}$ & $10.7 \%$ & $26 \%$ & $\begin{array}{l}40 \% \\
63.3 \%\end{array}$ & $28 \%$ & $22 \%$ & $50 \%$ \\
\hline 5.If I have cervical cancer, my whole life will change. & & & & & & \\
\hline 6.Thinking about cervical cancer frightens me. & $10.7 \%$ & $\begin{array}{c}60 \% \\
3470\end{array}$ & $29.3 \%$ & $28.7 \%$ & $49.3 \%$ & $22 \%$ \\
\hline 7.When I think of cervical cancer my heartbeats faster. & $\begin{array}{ll}10.7 \% \\
0.3 \%\end{array}$ & $34.7 \%$ & $54.7 \%$ & $28 \%$ & $28.7 \%$ & $43.3 \%$ \\
\hline 8.I think cervical cancer threatens my relationship with others. & $9.3 \%$ & $43.3 \%$ & $47.3 \%$ & $28 \%$ & $35.3 \%$ & $36.7 \%$ \\
\hline 9.Cervical cancer is a hopeless disease. & $\begin{array}{l}9.3 \% \\
0.3 \%\end{array}$ & $34.7 \%$ & $\begin{array}{c}56 \% \\
473 \%\end{array}$ & $28 \%$ & $29.3 \%$ & $42.7 \%$ \\
\hline $\begin{array}{l}\text { 10. The physical cost of cervical cancer is very large leading to an inability to } \\
\text { afford treatment. }\end{array}$ & $\begin{array}{l}9.3 \% \\
9.3 \%\end{array}$ & $\begin{array}{l}43.3 \% \\
26 \%\end{array}$ & $\begin{array}{l}41.3 \% \\
47.3 \%\end{array}$ & $\begin{array}{l}28 \% \\
28 \%\end{array}$ & $\begin{array}{l}36.1 \% \\
21.3 \%\end{array}$ & $\begin{array}{l}35.3 \% \\
50.7 \%\end{array}$ \\
\hline Total mean percentage of perceived severity & \multicolumn{3}{|c|}{$17.40 \pm 5.93$} & \multicolumn{3}{|c|}{$19.07 \pm 6.73$} \\
\hline \multicolumn{7}{|l|}{ Perceived barriers } \\
\hline 1.Getting cervical test would only make me worry & $14.7 \%$ & $33.3 \%$ & $52 \%$ & $31.3 \%$ & $26 \%$ & $42.7 \%$ \\
\hline 2.Screening is not necessary as there is no cure for cancer & $14 \%$ & $48.7 \%$ & $37.3 \%$ & $30.7 \%$ & $38.7 \%$ & $307 \%$ \\
\hline 3.The Pap screening is painful & $18 \%$ & $647 \%$ & $17.3 \%$ & $34.7 \%$ & $52 \%$ & $13.3 \%$ \\
\hline 4.It is too expensive to have a Pap screening or HPV vaccination & $4.7 \%$ & $57.3 \%$ & $38 \%$ & $21.3 \%$ & $47.3 \%$ & $31.3 \%$ \\
\hline 5.It is too embarrassing to have a Pap screening & $4.7 \%$ & $48 \%$ & $47.3 \%$ & $21.3 \%$ & $39.3 \%$ & $39.3 \%$ \\
\hline 6.I have not taken the Pap test because & $4.7 \%$ & $77.3 \%$ & $18 \%$ & $21.3 \%$ & $63.3 \%$ & $15.3 \%$ \\
\hline 7.I am afraid to find out if I have cancer & $4.7 \%$ & $76 \%$ & $19.3 \%$ & $21.3 \%$ & $62.7 \%$ & $16 \%$ \\
\hline 8.Do not know where I could go if I wanted to do a screening & $4.7 \%$ & $66.7 \%$ & $28.7 \%$ & $21.3 \%$ & $55.3 \%$ & $23.3 \%$ \\
\hline 9.I do not know at what age it is necessary to have a screening test & $4.7 \%$ & $67.3 \%$ & $28 \%$ & $21.3 \%$ & $55.3 \%$ & $23.3 \%$ \\
\hline 10. I do not know how often I need to get a Pap screening & $4.7 \%$ & $68 \%$ & $27.3 \%$ & $13.3 \%$ & $60.7 \%$ & $26 \%$ \\
\hline $\begin{array}{l}\text { 11. I think getting the HPV vaccination series might be unsafe or harmful to my } \\
\text { health. }\end{array}$ & $4.7 \%$ & $38 \%$ & $57.3 \%$ & $7.3 \%$ & $36.7 \%$ & $56 \%$ \\
\hline Total mean percentage of Perceived barriers & \multicolumn{3}{|c|}{$19.13 \pm 3.60$} & \multicolumn{3}{|c|}{$21.28 \pm 5.63$} \\
\hline
\end{tabular}




\section{perceived benefits}

1.A Pap screening can find cervical changes before they become cancer

2.If cervical changes are found early they are easily curable

3.It is important for a female to have a Pap screening so she will know if she is

healthy

4.The Pap screening can save my life

5.The innovative HPV vaccine is an effective primary prevention strategy for

cervical cancer.

Total mean percentage of perceived benefits

\begin{tabular}{l|c|} 
primary prevention strategy for & $\begin{array}{l}6.7 \% \\
6.7 \%\end{array}$ \\
\hline & $9.14 \pm 1.79$ \\
\hline
\end{tabular}

1.I eat a well-balanced diet

2.I always follow medical orders because I believe they will benefit my state of health

3.I frequently do things to improve my health

4.I take vitamins when I do not eat good meals

5.I search for new information related to my health

6.I have yearly physical examinations related to illness

7.I exercise regularly - at least three times a week.

\begin{tabular}{c|c|c}
$6.7 \%$ & $84 \%$ & $9.3 \%$ \\
$0.0 \%$ & $50 \%$ & $50 \%$ \\
& & \\
$0 \%$ & $60 \%$ & $40 \%$ \\
$0 \%$ & $100 \%$ & $0 \%$ \\
$0 \%$ & $100 \%$ & $0 \%$ \\
$0 \%$ & $100 \%$ & $0 \%$ \\
$0 \%$ & $100 \%$ & $0 \%$ \\
\hline
\end{tabular}

Total mean percentage of cues to action

\begin{tabular}{|c|c|c|c|}
\hline $27.3 \%$ & $34 \%$ & $48.7 \%$ & $17.3 \%$ \\
$18 \%$ & $34 \%$ & $54.7 \%$ & $11.3 \%$ \\
$38 \%$ & $34 \%$ & $36.7 \%$ & $29.3 \%$ \\
& \multicolumn{4}{|c|}{} & \\
& & & \\
$18.7 \%$ & $34 \%$ & $54 \%$ & $12 \%$ \\
$18 \%$ & $34 \%$ & $54.7 \%$ & $11.3 \%$ \\
\hline \multicolumn{4}{|c|}{$10.88 \pm 3.04$} \\
$9.3 \%$ & $82.7 \%$ & $16 \%$ & $1.3 \%$ \\
$50 \%$ & $61.3 \%$ & $18.7 \%$ & $20 \%$ \\
$40 \%$ & $44.7 \%$ & $31.3 \%$ & $24 \%$ \\
$0 \%$ & $50 \%$ & $50 \%$ & $0 \%$ \\
$0 \%$ & $43.3 \%$ & $56.7 \%$ & $0 \%$ \\
$0 \%$ & $71.3 \%$ & $28.7 \%$ & $0 \%$ \\
$0 \%$ & $55.3 \%$ & $44.7 \%$ & $0 \%$ \\
\hline
\end{tabular}




\section{Results}

Table (1): The study sample includes 75 women from PHC center and outpatient's clinic with the mean age of the sample was 39.25 \pm 6.08 year's old. About (44\%) had secondary school. More than two third of the sample $(77.3 \%)$ was from rural areas and $(66.7 \%)$ of them working. Additionally, two third of the sample had enough level of income (74.7\%) (Table, 1).

Table (2): As shown in table 2, the menarche mean age was $(11.92 \pm 0.91)$ years. About $(48 \%)$ were marriage more than 20 years. Regarding contraceptive methods $(26.7 \%)$ used the mechanical methods. Nearly, two third of the study sample (84\%) not performed Pap smear. Reason for not performing were Fear from result (28\%), Lack of knowledge $(52 \%)$ and, the test was expensive $(5.3 \%)$.

Table (3): It was observed in table (3) that the women had a satisfactory level, knowledge was $54.7 \%$ before intervention as compared to $5.3 \%$ after intervention, While, $86.7 \%$ of the study sample had good level of knowledge after intervention as compared to before $(5.3 \%)$ with statistical significant differences $(p=0.004)$ after intervention.

Table (4): Concerning health belief model constructs among the study sample before and after intervention, there was statistically significant difference regarding Perceived susceptibility, perceived benefits, and cues to action after the intervention $(\mathrm{p}<0.05)$ as compared to there is no statistically significant difference before and after intervention regarding perceived severity and perceived barrier $(=>0.05)$ (table, 4$)$.

Table (5): Shows the mean score of sub-scale of health belief model and study sample, there was increased in mean percentage after intervention among study sample (Perceived susceptibility, Perceived severity, Perceived barriers, perceived benefits and cues to action)

Table (6): Shows a correlation between perceived benefit, Perceived susceptibility, Perceived barriers and level of knowledge score before intervention $(\mathrm{p}<$ 0.05). While no statistical significant difference observed between knowledge level score and health belief model score after intervention regarding cues to action $(\mathrm{p}=>0.05)$.

\section{Discussion}

Cervical cancer is the easiest gynecologic cancer to prevent with regular screening tests and follow-up. It also is highly curable when found and treated early (CDC, 2019). Worldwide cervical cancer stays a chief public health issue and it is one of the most common gynecological cancer among women (Belglaiaa et al., 2017).
As regard to socio-demographic characteristics of the current study participants, the findings showed that, the mean age of the sample was $39.25 \pm 6.08$ years old and nearly half of them aged 30-40 years old. This explained the women were at late childbearing period, and they were in need to be aware of preventive measures about cervical cancer because the risk of cervical cancer is more. This result is in agreement with a study by Ahmed, et al., (2018) who instituted that, high percentage of the sample was in the age of 40 years. Moreover, this result was in line with the study conducted by Myriam et al. (2012) in Mexico who reported that, more than two-thirds of the participants were in this age. Equally, this result is in agreement with a study by Ehiemere et al. (2015) in Port Harcourt who found that more than one-third of the studied women was between twenty and forty-two years as this study was done among female working in the university.

Likewise, the results of this study indicated that, about half of the study participants had secondary school and slightly less than one fourth of them read \& write and had university level of education. More than two thirds of the participants were from rural areas. This is in accordance with Ahmed, et al., (2018) who illustrated that half of the sample had secondary education, and more than one-fifth of the sample had basic and university education, and only a minority of the sample was illiterate. Another supported findings by Wong et al. (2013) in Malaysia who found that more than half of the studied sample had secondary education and the minority of the sample was illiterate. On the other hand, this result inconsistent with the study findings by Duran (2014) in Turkey who found that the majority of the sample had university education.

Concerning to obstetric history, the current study showed that, the mean age of menarche $11.92 \pm$ 0.91 years and nearly half of the sample married after age 20 years old. These findings were matched with that reported by Shobeiri et al., (2016) in Iran who found that more than half of the sample married after the age of 20 years. Regarding to gravidity and parity, the results of this study revealed that, high percentage of women had high gravidity and parity. This is may be related to the culture of Saudi Arabian community that prefer big family and increased number of children. This finding is similar with that reported by Mupepi et al., (2011) in Zimbabwean who reported that more than two thirds had gravidity of three.

Furthermore, the current study findings revealed that more than half of the sample had used contraceptive methods to control childbirth intervals. This finding is 
in correspondence with Ahmed, et al., (2018), who found that all of the participants were using contraceptive methods. Moreover, Ehiemere,et al., (2015) in Jamaica who found that more than one-third do not use contraceptive methods.

Concerning to family history of cervical cancer, the present study showed that, very low percentage of the sample had history of cervical cancer owing to the lack of women awareness about cervical cancer. This finding is in similarity with Ahmed, et al., (2018) who found that, none of the participants had family history of cervical cancer. This might be related to lack of women knowledge regarding cervical cancer, as some women had family history of hysterectomy without knowing the reason. Also, Davidson and Suwan (2012) found that $0.6 \%$ of family history of cervical cancer was among young women in Thailand. In addition to women knowledge of pap smear test and obstacle to perform it, the current study illustrated that high percentage of women did not do Pap Smear test. While, the most common obstacle to perform Pap smear was lack of knowledge related this test and fear from result of this test. This finding is in agreement with Parsa, et al., (2017) who found that lack of laboratory facilities and traveling to city for testing were the most important barriers to Pap smear test among the rural women.

Regarding the level of knowledge among women before and after tele-nursing instruction about cervical cancer prevention based on HBM application; the current study results shows that the total mean score of knowledge reveal statistically significant differences after intervention $(p=0.004)$. An improvement was observed after receiving telenursing instruction based on HBM toward cervical cancer prevention; the majority of the women had satisfied level of knowledge about cervical cancer prevention after application. This finding is similar with that reported by Ahmed, et al., (2018) who illustrated that, all women had poor knowledge score about cervical cancer prevention before the program, which improved drastically after the program. This might be related to the effect of the nursing educational program on knowledge. Also, Pirzadeh and Mazaheri (2012) in Florida who found that knowledge mean score regarding Pap smear and cervical cancer before the intervention was low, whereas, it improved significantly after the educational intervention. As well as Rashwan et al. (2011) who detailed that, the students in Malaysia had deprived knowledge level of cervical cancer and its prevention.

Concerning the effectiveness of tele-nursing instruction about cervical cancer prevention based on
HBM on level of knowledge and belief of the participant women. According to (Vehei, et al., 2007 ; Al Seraty, \& Ali, 2014 ) designated HBM which asserts that to plan a successful educational intervention, the individual or group's perceived susceptibility; perceived severity and its consequences; perceived benefits in taking certain actions to reduce risk of cervical cancer; perceived barriers and cues to action are required.

Regarding the mean score of sub-scale of HBM, the current study explicated that, there was an increase in mean percentage after intervention among study sample. This was due to the effect of tele-nursing instruction and its fastness, and easy to find complete information on time the women need. In addition to application of HBM in changing behavior and knowledge in identification of the severity and benefits regarding to cervical cancer prevention. This finding was in agreement with (Ahmed et al., 2018) who found that, the study sample after the program got significantly increase scores regarding the perceived susceptibility, the perceived severity, the perceived barriers, the perceived benefits and the cues to action compared with the scores before the program. Parallel findings were gained in a study carried out on students in Faculties of Benha University by Yossif and EL Sayed (2014), who found that after application of self-learning package, there was a significant development in all HBM constructs. Moreover, these results are in agreement with a study approved in Iran by Shojaeizadeh et al., (2011) who discovered that education based on HBM was active and improve the perceived susceptibility, severity, benefits, and barriers.

Regarding to correlation between total knowledge score and total sub-scale of belief among study sample before \& after tele-nursing instruction, the results revealed that, there was significant correlation between perceived benefit and level of knowledge score before intervention $(\mathrm{P}<0.03)$. While there was significant correlation between the level of knowledge score and health belief model score after intervention, where Perceived susceptibility $(\mathrm{P}<0.05)$, Perceived barriers $(P=0.00)$, perceived benefits $(P=0.001)$ and cues to action $(\mathrm{P}=0.03$ ) among the study sample. While there was no statistically significant difference between the level of knowledge score and health belief model score after intervention regarding perceived severity $(\mathrm{P}=>0.05)$. This finding agreed with Shojaeizadeh, (2011) who found that all components of HBM mean score were significantly increased after intervention compared to preintervention. These findings were consistent with results of many previous researches. Furthermore, 
Yakhforoushha, etal (2009) evaluated the consequence of training on the voluntary health workers' knowledge and attitude regarding Pap test using HBM.

The Health Belief Model (HBM) model has proven impressive successes in improving both the behavior of individuals and groups, as well as the level of their information after applying it in more than one educational program. Such as with Hazavehei (2007) who conducted an educational program in Garmsar City for students using HBM to study the protective behavior of the participants regarding osteoporosis. Also, Sharifi-Rad (2007) who evaluated the effect of health education using HBM on preventive action against smoking among high school students. All these previous studies revealed that both knowledge and attitude of the participants significantly improved after training program. Moreover, many previous studies that dealt with the application of this model, for example Kang \& Kim (2011); Juntasopeepun et al. (2012); \& Johnson et al. (2013).

\section{Conclusion:}

It can be concluded that, tele-nursing instruction through the application of the Health Belief Model (HBM) proved massive changes in improving both the beliefs of the participating women, as well as the level of their knowledge about cervical cancer prevention.

\section{Recommendations:}

Enhancement of tele-nursing instruction use in many nursing practice settings and developing future research prevention programs.

\section{References:}

- Abolfotouh, M., Ala'a, A., Mahfouz, A., AlAssiri, M., Al-Juhani, A., \& Alaskar, A., (2015): Using the health belief model to predict breast selfexamination among Saudi women. BMC Public Health, 15(1), 1163.

- Ahmed, S.R, Esa, A.S, \& El-zayat, O.S. (2018): Health Belief Model-based educational program about cervical cancer prevention on women knowledge and beliefs, Egyptian Nursing Journal, Vol.15, issue 1, p.p: 39-49.

- Al Seraty, \& Ali., (2014): Health Belief Model Based Intervention for Improving Nursing Students' Knowledge and Behavior Regarding Osteoporosis Prevention, Journal of Biology, Agriculture and Healthcare, Vol.4, No.7.

- Aldohaian, A., Alshammari, S., \& Arafah, D., (2019): Using the health belief model to assess beliefs and behaviors regarding cervical cancer screening among Saudi women: a cross-sectional observational study. BMC women's health, 19(1), 6.

- Alkhalawi, E., Al-Madouj, A., \& Al-Zahrani, A. (2019): Cervical Cancer Incidence and Trends among Nationals of the Gulf Cooperation Council States, 1998-2012. The Gulf journal of oncology, 1(31), 7-13.

- Al-Mandeel, H., Sagr, E., Sait, K., Latifah, H., Al-Obaid, A., Al-Badawi, I., \& Mustafa, R., (2016): Clinical practice guidelines on the screening and treatment of precancerous lesions for cervical cancer prevention in Saudi Arabia. Annals of Saudi medicine, 36(5), 313-320.

- Alnafisah, R., Alsuhaibani, R., Alharbi, M., Alsohaibani, A., \& Ismail, A., (2019): Saudi Women's Knowledge and Attitude toward Cervical Cancer Screening, Treatment, and Prevention: A Cross-Sectional Study in Qassim Region (20182019). Asian Pacific Journal of Cancer Prevention, 20(10), 2965-2969.

- Alreshidi, F., Abdalla, R., \& Ahmed, H., (2020): Acceptance and merit of Pap. Test for prevention and early detection of cervical cancer among Saudi women in Hail Region. Medical Science, 24(103), 1669-1676.

- Alsbeih G. (2014): HPV infection in cervical and other cancers in Saudi Arabia: implication for prevention and vaccination. Front Oncol 2014;4. https://doi.

- Al-Zahrani DAS. Cancer Incidence Report Saudi Arabia.

2014. https://nhic.gov.sa/eServices/Documents/2014 .pdf. Accessed 7 Aug 2018.

- Amotsuka, C., (2013): Community Based Cervical Cancer Screening. Lecture Delivered at the West African Framework Program for Global Health at Center for Bioethics. Ibadan: Ashi; 2007. Available at

http://www.powershow.com/view/fd704MDQ2M/C ommunitybased_Cervical_Cancer_Screening and intention to obtain vaccine among Korean female undergraduate students. Women Health 51:759-776.

- Anyebe, E., Opaluwa, S., Muktar, H., \& Philip, F., (2014): Knowledge and practice of cervical cancer screening amongst nurses in Ahmadu Bello University Teaching Hospital Zaria. Cancer, 4(27), 33-40.

- Arbyn M, Weiderpass E, Bruni L., (2020): Estimates of incidence and Mortality of cervical cancer in 2018: a worldwide analysis. Lancet Glob Health 2020; 8(2):e191-e203.

- Asiyeh Pirzadeh and Maryam Amidi Mazaheri. (2012): The Effect of Education on Women's 
Practice Based on the Health Belief Model About Pap Smear Test, International Journal of Preventive Medicine, Aug;3(8):585-90.

- Becker, S., Miron-Shatz, T., Schumacher, N., Krocza, J., Diamantidis, C., \& Albrecht, U. V. (2014): M Health 2.0: experiences, possibilities, and perspectives. JMIR mHealth and uHealth, 2(2), e24.

- Belglaiaa E., Souho T., Badaoui L., (2017): Awareness of cervical cancer among women attending an HIV treatment centre: a cross-sectional study from Morocco.BMJ 2017-020343.

- Bodurka, B., Morris, M., Eifel, P., Levenback, C., Bevers, M., Lucas, K., (2011): Women with cervical cancer: an outcomes analysis. GynecolOncol 78: 187-193.

- Castle PE, Pierz A. (2019): (At Least) Once in Her Lifetime: Global Cervical Cancer Prevention. ObstetGynecolClin North Am 2019; 46(1):107-123.

- Centers for Disease Control and Prevention. 2019. https://www.cdc.gov/cancer/knowledge

- Davidson P., Suwan N., (2012): Human Papillomavirus vaccination intention among young women in Thailand. Asian Pac J Cancer Prev 13:3213-3219.

- Dunk, N., Chung, Y., Compton, D., \& Callaghan, J., (2004): The reliability of quantifying upright standing postures as a baseline diagnostic clinical tool. Journal of manipulative and physiological therapeutics, 27(2), 91-96.

- Duran ET (2014): Examination with the health belief model of women's attitudes to cervical cancer and early diagnosis in Turkey: a qualitative study. Asian Pac J Cancer Prev 12:2014.

- Ehiemere IO, Maureen F, Robinson BGC (2015): Attitude and practice of cervical cancer screening among female health workers in university of PortHarcourt teaching hospital, Rivers State. J Res Nurs Midwifery 4:072-082.

- Ferdous, J., Khatun, S., Ferdous, N., Sharmin, F., Akhter, L., \& Keya, K., (2016): Attitude and practice of cervical cancer screening among the female doctors of Bangabandhu sheikh Mujib Medical University. Bangladesh Medical Journal, 45(2), 66-71.

- Ferlay, J., Soerjomataram, I., Dikshit, R., Eser, S., Mathers, C., Rebelo, M., \& Bray, F. (2015): Cancer incidence and mortality worldwide: sources, methods and major patterns in GLOBOCAN 2012. International journal of cancer, 136(5), E359-E386.

- Johnson CE, Mues KE, Mayne SL, Kiblawi AN (2013): Cervical cancer screening among immigrants and ethnic minorities: a systematic review using the Health Belief Model. J Genit Tract Dis 12:232-241.
- Juntasopeepun P, Davidson P, Suwan N, Phianmongkhol Y, Srisomboon J.,(2012): Human papillomavirus vaccination intention among young women in Thailand. Asian Pac J Cancer Prev 13:3213-3219.

- Kang H, Kim J., (2011): Knowledge, attitudes of human Papillomavirus vaccine, Women \& Health 51(8):759-76.

- Kumar, V., Abbas, A. , Fausto, N., \& Mitchell, R. (2007): Chapter 19 the female genital system and breast. Robbins basic pathology. 8th ed. Philadelphia: Saunders: 718-721.

- Mali, N. (2014): Effect of structured education on knowledge regarding prevention of cervical cancer among A.N.M. students. Int J Sci Res 3:2319-7064.

- McEwen, M. \& Wills, E.M., (2014): Theoretical Basis for Nursing, Fourth edition, Philadelphia. Lippincott Williams \& Wilkins.

- Massarat A, Samadi N, Mehrnoush N, Mohammadi $R$ and Zali M.(2011): Remote Nursing: A suitable choice for improving the patient training process: Journal of Health Care 3. 2011; Page 47-52

- McGonigle D, Mastrian K. (2008): Nursing Informatics and the Foundation of Knowledge. first Edition. Sudbury: Jones \& Bartlett Publishers. 2008.

- Mupepi SC, Sampselle CM, and Johnson TRB (2011): Knowledge, attitudes, and demographic factors influencing cervical cancer screening behavior of Zimbabwean women. J Women's Health 20:943-952.

- Myriam L, Theresa B, Patrick T., (2012): Attitudes towards cervical cancer screening: a study of beliefs among women in Mexico Calif. J Health Promot 4:13-24.

- Naik, P., Nagaraj, K., Nirgude, A. (2012): Awareness of cervical cancer and effectiveness of educational intervention programme among nursing students in a rural area of Andhra Pradesh, health line. CABI 3:41-445.

- Nwankwo, K., Aniebue, U., Aguwa, E., Anarado, A., \& Agunwah, E. (2011): Knowledge attitudes and practices of cervical cancer screening among urban and rural Nigerian women: a call for education and mass screening. European journal of cancer care, 20(3), 362-367.

- Obstetricians, R., (2003): Safety, acceptability, and feasibility of a single-visit approach to cervicalcancer prevention in rural Thailand: a demonstration project. The lancet, 361(9360), 814-820.

- Oche, M., Kaoje, A., Gana, \& Ango, J., (2013): Cancer of the cervix and cervical screening: Current knowledge, attitude and practices of female health 
workers in Sokoto, Nigeria. International Journal, 5(3), 106-109.

- Ogden, K. (2009): Health education and health promotion. An application of an extended health belief model. Wageningen Academic Publishers, Wageningen University: Wageningen.

- Parsa P , Sharifi F , Shobeiri F \& Karami M (2017): Effects of Group Counseling Based on Health Belief Model on Cervical Cancer Screening Beliefs and Performance of Rural Women in Kaboudrahang, Iran, Asian Pac J Cancer Prev, 18 (6), 1525-1530

- Pirzadeh A \& Mazaheri M.( 2012): The effect of education on women's practice based on the Health Belief Modelabout pap smear test. Int J Prev Med. 2012;6:365-72. [PMC free article] [PubMed] [Google Scholar]

- Rashwan, H., Lubis, S.L. \& Ni, K.A. (2011): Knowledge of cervical cancer and acceptance of HPV vaccination among secondary school students in Sarawak, Malaysia. Asian Pacific Journal of Cancer Prevention 12(7): 1837-1841. doi:10.1016/j.smim.2009.02.004

- Richardson LA, Tota J, Franco EL. (2011): Optimizing technology for cervical cancer screening in high-resource settings. Exp Rev Obstet Gynecol 2011;6(3):343-53. https://doi.org/10.1586/eog.11.13.https://www.ncbi. nlm.nih.gov/pubmed/26617667.

- Schlachta-Fairchild, L.,(2015): Telehealth and telenursing are live: APN policy and practice implications. The Journal for Nurse Practitioners, 6(2):98-106.

- Sharifi-Rad G, Hazavei MM, Hasan-Zadeh A, Danesh-Amouz A.( 2007): The effect of health education based on health belief model on preventive actions of smoking in grade one, middle school students. Arak University of Medical Sciences Journal. 2007;10(1):79-86. [Persian]

- Shobeiri F, Javad MT, Parsa P, Roshanaei G (2016): Effects of group training based on the Health Belief Model on knowledge and behavior regarding the pap smear test in Iranian women: A quasi-experimental study. Asian Pac J Cancer Prev 17:2871-2876.

- Shojaeizadeh, D., Hashemi, S., Moeini, B., \& Poorolajal, J. (2011): The effect of educational program on increasing cervical cancer screening behavior among women in Hamadan, Iran: Applying health belief model. Journal of Research in Health Sciences, 1(1), 20-25.

- U.S. Department of Health and Human Services. (2020): Health Resources \& Services Administration. Telehealth Programs. Available at https://www.hrsa.gov/ruralhealth/telehealth/index.html.

- Urasa, M., Darj, E. (2011): Knowledge of cervical cancer and screening practices of nurses at a regional hospital in Tanzania. African Health Sciences 2011; 11(1): 48-57.

- Vehei H., Taghdisi M \& Saidi M. (2007): Application of the health belief model for osteoporosis prevention among middle school girl students, Garmsar, Iran, education for health journal, 20 (1): 1-11.

- Whitehead, L., \& Seaton, P. (2016): The effectiveness of self-management mobile phone and tablet apps in long-term condition management: a systematic review. Journal of medical Internet research, 18(5), e97.

- Wong LP, Khoo EM, \& Shuib R (2013): Knowledge and awareness of cervical cancer and screening among Malaysian women who have never had a Papsmear: a qualitative study. Singapore Med J 50:49.

- World Health Organization, (2018): Information Centre (ICO) on HPV and Cancer (2016). Human papillomavirus and related cancers, fact sheet 2016, Available

at: http://www.hpvcentre.net/statistics/reports/EGY_FS .pdf.

- Yakhforoushha A., Solhi M., Ebadifard A., (2009): Effects of education via health belief model on knowledge and attitude of voluntary health workers regarding Pap smear in urban centers of Ghazvin. Faculty of Nrsing of Mdwifery Quarterly. 2009;18(63):25-30.[Persian].

- Yakout, S., Moawed, S., \& Gemeay, E., (2016): Cervical Cancer and screening test (PAP test): knowledge and beliefs of Egyptian women. Am J Nurs Sci, 5, 175-184.

- Yossif, H.A, EL Sayed, H.A (2014): Effect of selflearning package based on health. IOSR Journal of Nursing and Health Science, Volume 3, Issue 6 Ver. IV (Nov.-Dec. 2014), PP: 77- 88.

- Zakeri Moghadam, M., Basampur, S., Rajab, A., Faghihzadeh, S., \& Nesari, M. (2009): Effect of telephone follow-up by a nurse (Tele Nursing) on dietary adherence in patients with diabetes mellitus type II. Journal of Faculty of Nursing and Midwifery Tehran University of Medical Sciences (HAYAT), 14(2), 63-71. 